\title{
Reconciling disparate prevalence rates of PTSD in large samples of US male Vietnam veterans and their controls William W Thompson ${ }^{1}$, Irving I Gottesman*2 and Christine Zalewski ${ }^{3}$
}

\author{
Address: ${ }^{1}$ Immunization Safety Office, US Centers for Disease Control and Prevention, Atlanta, GA, USA, ${ }^{2}$ Departments of Psychiatry and \\ Psychology, University of Minnesota, Minneapolis, MN, USA and 3Pacific Graduate School of Psychology, Palo Alto, CA, USA \\ Email: William W Thompson - wct2@cdc.gov; Irving I Gottesman* - gotte003@umn.edu; Christine Zalewski - cez@comcast.net \\ * Corresponding author
}

Published: 02 May 2006

BMC Psychiatry 2006, 6:19 doi:10.1186/1471-244X-6-19
Received: 09 January 2006

Accepted: 02 May 2006

This article is available from: http://www.biomedcentral.com/I47I-244X/6/19

(c) 2006 Thompson et al; licensee BioMed Central Ltd.

This is an Open Access article distributed under the terms of the Creative Commons Attribution License (http://creativecommons.org/licenses/by/2.0), which permits unrestricted use, distribution, and reproduction in any medium, provided the original work is properly cited.

\begin{abstract}
Background: Two large independent studies funded by the US government have assessed the impact of the Vietnam War on the prevalence of PTSD in US veterans. The National Vietnam Veterans Readjustment Study (NVVRS) estimated the current PTSD prevalence to be $15.2 \%$ while the Vietnam Experience Study (VES) estimated the prevalence to be $2.2 \%$. We compared alternative criteria for estimating the prevalence of PTSD using the NVVRS and VES public use data sets collected more than 10 years after the United States withdrew troops from Vietnam.

Methods: We applied uniform diagnostic procedures to the male veterans from the NVVRS and VES to estimate PTSD prevalences based on varying criteria including one-month and lifetime prevalence estimates, combat and non-combat prevalence estimates, and prevalence estimates using both single and multiple indicator models.

Results: Using a narrow and specific set of criteria, we derived current prevalence estimates for combat-related PTSD of $2.5 \%$ and $2.9 \%$ for the VES and the NVVRS, respectively. Using a more broad and sensitive set of criteria, we derived current prevalence estimates for combat-related PTSD of $12.2 \%$ and $15.8 \%$ for the VES and NVVRS, respectively.

Conclusion: When comparable methods were applied to available data we reconciled disparate results and estimated similar current prevalences for both narrow and broad definitions of combatrelated diagnoses of PTSD.
\end{abstract}

\section{Background}

The systematic examination of combat-related stress disorders has been ongoing since the end of World War I. [15] In 1980, Post-Traumatic Stress Disorder (PTSD) first appeared as a formal diagnosis in DSM-III [6-9] and has periodically been the focus of debate regarding appropriate definition, symptom criteria, and etiology. [10-16] The potential traumas associated with the diagnosis of PTSD are heterogeneous and include military battle, vio- lent sexual attacks, and natural disasters. [17-22] Many studies have demonstrated that PTSD symptoms persist over time and can emerge or re-emerge long after the occurrence of the original trauma, given another "trigger". [19,21,23-36] Certain traumas such as wartime combat or incarceration as a prisoner of war typically lead to more pronounced and longer lasting PTSD symptoms. Individual differences in response to severe traumas are well documented, and both environmental and biological factors 
have been found to moderate the subsequent experience of stress-related symptoms. [37-45] Finally, a recent study has suggested that rates of combat-related PTSD may be inflated because some individuals report experiencing a traumatic combat exposure when in fact there is little objective evidence to support their claims. [46-48]

A number of different instruments have been developed over the last two decades to measure or diagnose PTSD including the Structured Clinical Interview (SCID), [6,4951] alternative versions of the PTSD module of the Diagnostic Interview Schedule (DIS), [52-59] the Mississippi Scale for Combat-Related PTSD (MISS-PTSD) [60-64], and the PTSD sub-scale of the Minnesota Multiphasic Personality Inventory (MMPI-PTSD) [65-71]. The instruments used for diagnosing PTSD have varying reliabilities. The psychometric properties of the MISS-PTSD have been studied extensively, supporting the reliability and validity of the instrument. [72-74] The psychometric properties of the MMPI-PTSD have been studied less often and the measure has been criticized for being a non-specific measure of response to severe trauma. $[67,75]$

The two largest and most comprehensive studies to examine the impact of the Vietnam War on Vietnam-veterans were carried out more than a decade after the US pulled military troops out of Vietnam. The National Vietnam Veteran Readjustment Study [19,76-79] assessed a nationally representative sample of male Vietnam Theater-Veterans, male Vietnam Era-Controls, male civilian controls, and female veterans and civilian controls. The Vietnam Experience Study (VES) $[21,80,81]$ randomly sampled male Vietnam Theater-Veteran Army draftees and male Army Vietnam Era-Control draftees. Although both studies were conducted at approximately the same time and examined large representative samples of male veterans, the published studies reported disparate current and lifetime rates of PTSD. Specifically, the NVVRS reported the current prevalence rate of PTSD to be 15.2\% [19,76] whereas the VES reported a current prevalence rate of 2.2\%. [21] Previous attempts have been made to describe the similarities and differences between the NVVRS and VES methodologies [82] and the authors concluded that the NVVRS sample was the only study appropriate for extrapolating national PTSD prevalence estimates because the VES used an invalid PTSD diagnostic instrument. The present investigation examined the methodologies used by the two studies and provides a reanalysis of the data in an effort to provide a more coherent explanation for the reported discrepancies.

\section{Methods NVVRS method}

The NVVRS used an area probability approach from the military records of 8.2 million veterans. The sample included both men and women, enlisted and officers, and represented all branches of the military. They obtained data from a sample of male Vietnam Theater-Veterans ( $\mathrm{n}$ $=1,200)$ and male Vietnam Era-Controls $(\mathrm{n}=424)$, as well as from female veterans and both male and female civilians controls. Additional details of the sampling procedure are described elsewhere. [19] We report data only for the male Veterans in this report.

The diagnostic methods in the NVVRS were complex. Initially, a clinical subsample that disproportionately included PTSD subjects from both the Vietnam TheaterVeterans $(n=344)$ and Vietnam-Era Veterans $(n=96)$ was used to develop a series of logistic regression models that predicted a complex dichotomous variable based on multiple measures of PTSD. Subjects for the clinical subsample were selected to be within reasonable commuting distance of 28 specific Standard Metropolitan Statistical Areas (i.e., no farther than 75 miles from any of the 28 geographic areas). The clinical subsample included "apparent" PTSD cases and apparent non-cases. The apparent non-cases were selected to maximize the likelihood of detecting false negatives by over-sampling individuals with high scores on a combat exposure index and/ or reporting nonspecific psychological distress.

The dichotomous outcome used for the clinical subsample logistic regression analyses was a composite PTSD diagnosis that comprised the MISS-PTSD[60], the Keane MMPIPTSD sub-scale [65], and a semi-structured diagnostic interview based on FORM NP-V of the Structured Clinical Interview for DSM-III-R (SCID) [50,51,83]. Rules for interpreting and combining results from the three different instruments have been published previously. [82] The predictors for the logistic regression equations included the total score from the MISS-PTSD and the total number of PTSD symptoms reported from a structured diagnostic PTSD interview developed in the style similar to the Diagnostic Interview Schedule (D-PTSD). [53,56,84,85] The results of the logistic regression models from the clinical subsample were subsequently used to extrapolated prevalence estimates for PTSD for the entire NVVRS sample who were all administered the MISS-PTSD and the D-PTSD.

\section{VES methods}

For the VES, 48,513 records were randomly sampled from an initial population of 4.9 million U.S. Army records. Records were selected for the study based on the following six criteria: 1) male veteran, 2) military occupational specialty (MOS) other than duty soldier or trainee, 3 ) single term of enlistment, 4) minimum of 16 weeks of active service time, 5) pay grade E-1 to E-5 at discharge, and 6) entered the military for the first time between January 1 , 1965 and December 31, 1971. Only veterans who served in Vietnam at some time during their enlistment were 
included in the Vietnam Theater sample. To be included in the Vietnam-Era Control group, the veteran must have served at least one tour of duty in Germany, Korea, or the United States during the same time period, and never have served in the Army in Vietnam. The sample used to estimate PTSD prevalence rates in the VES was comprised of 4,462 veterans who voluntarily participated in an intensive one-week medical and psychological evaluation in 1985 and 1986. The sample was randomly drawn from a larger random sample of 15,288 veterans who participated in the telephone interview component of the VES. Both of these samples, as well as characteristics of nonrespondents, are described in detail elsewhere. $[21,86,87]$

All subjects were administered a modified version of the Diagnostic Interview Schedule III-A (DIS-III-A), which included a PTSD module. Details of the DIS-III-A modifications have been documented previously. [87] In articles published by the CDC, [21] PTSD prevalence estimates were based solely on whether or not veterans met the diagnostic criteria for combat-related PTSD using the modified DIS-III-A. The MMPI was administered to all veterans and would have allowed for the scoring of the MMPI-PTSD sub-scale, but these results were not incorporated into published findings.

\section{Comparison of PTSD prevalence estimates for the VES and NVVRS}

The primary comparisons for the two studies focused on the DSM-III-R criteria for combat-related PTSD. We also included alternative definitions of combat-related PTSD using criteria from both DSM-III and DSM-III-R. The DSM-III-R Manual [88] requires at least 6 symptoms for PTSD: one B-Criteria symptom, three C-Criteria symptoms, and two symptoms the D-Criteria symptoms. There are a total of 17 symptoms or probes that comprise the criteria: four B-Criteria symptoms, seven C-Criteria symptoms, and six D-Criteria symptoms.

Modified versions of the PTSD module from the Diagnostic Interview Schedule were the only instruments that were administered to all subjects in both studies. For the NVVRS, the D-PTSD module included 21 symptom probes, while the VES DIS-III-A PTSD module included only 9 symptom probes. Therefore, the NVVRS sampled more than the standard 17 DSM-III-R symptoms associated with PTSD while the VES sampled fewer probes.

The MMPI-PTSD was administered to all subjects in the VES and to the clinical sub-sample of the NVVRS. The MMPI-PTSD scale has been used with a number of different cutting-scores based on the types of cases who were important to identify and to differentiate. For example, low cutting-scores of 13 and 14.5 have been used in studies where investigators wanted to minimize the identifica- tion of false-negatives while a cutting-score of 30 has been used in studies where the investigators wanted to minimize the identification of false positives. $[65,70,71]$ The MISS-PTSD was administered only to subjects in the NVVRS. A similarly sensitive cutting-score of 89 has been used in studies where investigators wanted to minimize the identification of false-negatives while a specific threshold of 107 has been used when attempting to minimize the identification of false positives. $[19,60]$

For the purposes of comparisons across the two studies, we constructed several alternative composite diagnoses. For the NVVRS, the D-PTSD and the MISS-PTSD were administered to all subjects in the total sample, and therefore these instruments were used to develop a composite diagnosis for combat-related-PTSD for the NVVRS sample. For the composite diagnosis, a score of 94 was used for the MISSPTSD. Previous research has suggested that a score of 94 provides the most reliable estimate of the PTSD prevalence rate for Vietnam Veterans. [19] For the VES, the DIS-III-A PTSD and the MMPI-PTSD were administered to all subjects in the sample; thus these instruments were used to develop a multiple indicator diagnosis of combat-relatedPTSD for the VES sample. For the composite diagnosis, a cutting-score of 26 was used for the MMPI-PTSD scale. The composite diagnosis was defined as a variable that ranged from zero to two and was estimated by summing the dichotomously coded variables from the two instruments used to estimate the prevalences. The composite score was then recoded into a "narrow" PTSD definition and a "broad" PTSD definition. For example, for the NVVRS, the D-PTSD and the MISS-PTSD were the two instruments used to provide the final diagnosis for PTSD. A person who was positively diagnosed with both the D-PTSD and the MISSPTSD instruments would have been classified as a hit for both the narrow PTSD definition and the broad PTSD definition. A person who was diagnosed positively with just one of the two instruments would have been classified as a hit for only the broad PTSD definition. The results for the narrow definition are over-weighted toward the prevalence from the instrument with the lowest prevalence, while the results for the broad definition are overweighted toward the prevalence of the instrument with the highest prevalence. We were unable to make sensitivity and specificity estimates for either study because we did not have a gold standard measure. We were also unable to make direct comparisons of overlapping items from the two studies because many of the items from the DSM-III criteria were split into several different items in the DSM-III-R criteria.

Based on feedback from one of our reviewers, we carried out an analysis using the NVVRS sample comparing subjects who were "VES-Like" to subjects who were "NonVES-Like". A similar analysis has been carried out previously on one of the outcome measures.[82] 
Table I: PTSD Items Administered Using D-PTSD Scale in NVVRS

\begin{tabular}{|c|c|c|c|c|c|c|c|}
\hline \multicolumn{2}{|c|}{$\begin{array}{l}\text { DSM-III-R Symptoms Occurring in Last } 30 \text { Days } \\
\text { Criteria }\end{array}$} & \multicolumn{3}{|c|}{$\begin{array}{l}\text { Male Vietnam Theater } \\
\text { Veterans }\end{array}$} & \multicolumn{3}{|c|}{ Male Vietnam Era Controls } \\
\hline & & $\mathbf{N}$ & Prev (\%) & $95 \% \mathrm{Cl}$ & $\mathbf{N}$ & Prev (\%) & $95 \% \mathrm{Cl}$ \\
\hline \multirow[t]{5}{*}{ B } & Unpleasant memories & 1183 & 2.7 & $1.7-3.8$ & 410 & 1.1 & $0.0-2.3$ \\
\hline & Disturbing memories & 1182 & 3.4 & $2.1-4.6$ & 406 & 1.8 & $0.0-3.5$ \\
\hline & Felt as if event recurring & 1181 & 3.2 & $1.9-4.5$ & 406 & 1.0 & $0.0-2.3$ \\
\hline & Flashbacks & 1179 & 1.8 & $0.9-2.7$ & 404 & 0.5 & $0.0-1.3$ \\
\hline & Suddenly feeling anxious/fearful/panicky & 1187 & 3.3 & $2.0-4.7$ & 407 & 0.3 & $0.0-0.5$ \\
\hline \multirow[t]{9}{*}{$\mathbf{C}$} & Tried not to think about previous events & 1179 & 3.1 & $1.9-4.4$ & 408 & 0.7 & $0.0-1.5$ \\
\hline & Avoided feelings about previous events & 1185 & 2.8 & $1.6-4.0$ & 403 & 0.3 & $0.0-1.0$ \\
\hline & Avoided certain places or activities & 1190 & 1.3 & $0.6-2.1$ & 410 & 1.3 & $0.0-2.8$ \\
\hline & Could not remember portions of traumatic event & 1169 & 1.8 & $0.8-2.8$ & 406 & 0.0 & $0.0-0.1$ \\
\hline & Lost interest in activities & 1188 & 2.8 & $1.6-4.0$ & 410 & 1.2 & $0.0-2.5$ \\
\hline & Stopped caring about activities & 1190 & 2.0 & $1.0-3.0$ & 411 & 1.4 & $0.0-2.9$ \\
\hline & Felt cut off from people & 1186 & 4.1 & $2.6-5.5$ & 410 & 1.4 & $0.0-2.9$ \\
\hline & Felt numb or empty inside & 1191 & 2.3 & 1.2-3.4 & 411 & 1.2 & $0.0-2.4$ \\
\hline & Could not feel things anymore & 1189 & 2.5 & $1.4-3.6$ & 408 & 0.6 & $0.0-1.6$ \\
\hline \multirow[t]{7}{*}{ D } & Difficulty falling asleep & 1182 & 5.9 & 4.1-7.6 & 410 & 2.2 & $0.5-3.9$ \\
\hline & Felt as if you might get out of control & 1185 & 1.5 & $0.7-2.3$ & 406 & 1.0 & $0.0-2.2$ \\
\hline & Minor events bothered you/made you angry & 1189 & 3.1 & $1.9-4.3$ & 411 & 2.6 & $0.1-4.7$ \\
\hline & Trouble concentrating & 1192 & 2.8 & $1.7-3.9$ & 412 & 1.2 & $0.1-2.3$ \\
\hline & Felt you had to stay on guard & 1190 & 3.4 & $2.1-4.7$ & 409 & 2.0 & $0.1-3.8$ \\
\hline & Spells or panic attacks due to previous memory & 1175 & 0.9 & $0.3-1.4$ & 407 & 0.0 & NA \\
\hline & Unexpected noises startle you & 1190 & 3.6 & $2.2-5.0$ & 412 & 1.1 & $0.0-2.3$ \\
\hline
\end{tabular}

I. Confidence Intervals that were less than 0 were truncated to 0 .

\section{Results \\ NVVRS}

NVVRS total sample

The weighted prevalence estimates for DSM-III-R PTSD symptoms occurring currently (i.e. symptoms occurring within the last month), using the D-PTSD scale from the NVVRS, are presented in Table 1. For Criterion B symptoms, using DSM-III-R rules, the current prevalence estimates for the male Vietnam Theater-Veterans ranged from $1.8 \%$ for "flashbacks" to $3.4 \%$ for "disturbing memories". For the male Vietnam-Era Controls, the Criterion B symptom current prevalences ranged from $0.3 \%$ for "sudden anxious feeling" to $1.8 \%$ for "disturbing memories". For the criterion $\mathrm{C}$ symptoms, the highest current prevalence rate was "feeling cut off from people" for both groups of veterans. Finally, for Criterion D symptoms, the highest current prevalence estimate for the Theater-Veterans was "difficulty falling asleep" (5.9\%). For the Era-Controls, the highest current prevalence was for "minor events making you angry" (2.6\%).

The weighted prevalence estimates for two different measures of PTSD used in the NVVRS sample are presented in Table 2. For the male Vietnam Theater-Veterans, PTSD prevalence estimates using the MISS-PTSD ranged from $6.0 \%$ to $20.9 \%$ depending on the cutting-score used. Current PTSD prevalence estimates using the D-PTSD were $3.3 \%$ for combat-related PTSD and 3.5\% for PTSD due to any trauma. For lifetime PTSD prevalence estimates using the D-PTSD, the estimates were $7.9 \%$ and $8.9 \%$ for these same veterans.

As expected, for the male Vietnam-Era Controls, current and lifetime PTSD prevalence estimates were substantially lower and ranged from $3.8 \%$ to $11.2 \%$ using the MISSPTSD. Current PTSD prevalence estimates using the DPTSD were $0.0 \%$ for combat-related PTSD and $1.6 \%$ for all-cause PTSD. Lifetime combat-related PTSD prevalence estimates using the D-PTSD were also quite low relative to the male Vietnam Theater-Veterans with prevalence of $0.1 \%$ for combat-related PTSD and to $4.6 \%$ for the allcause PTSD.

\section{Clinical subsample}

Three PTSD instruments were administered to the NVVRS clinical sub-sample (i.e., MISS-PTSD, MMPI-PTSD, and the D-PTSD). The weighted prevalence estimates for the PTSD scales obtained from the clinical subsample are presented in Table 3. For the male Vietnam Theater-Veterans, the PTSD prevalence estimates ranged from $7.0 \%$ to $20.4 \%$ using the MISS-PTSD measure and ranged from 3.8 to 14.5 using the MMPI-PTSD instrument. For current PTSD prevalence rates using the D-PTSD, estimates were 3.3\% and $3.4 \%$ for the male Vietnam Theater-Veterans. For lifetime PTSD prevalences using the D-PTSD, the estimates were $10.8 \%$ and $10.1 \%$ for the all-cause and combat related 
Table 2: PTSD Scales Administered to Entire NVVRS Sample

\begin{tabular}{|c|c|c|c|c|c|c|c|}
\hline \multirow[t]{2}{*}{ Scale } & \multirow[t]{2}{*}{ Criteria } & \multicolumn{3}{|c|}{$\begin{array}{c}\text { Male Vietnam Theater } \\
\text { Veterans }\end{array}$} & \multicolumn{3}{|c|}{ Male Vietnam Era Controls } \\
\hline & & $\mathbf{N}$ & Prev (\%) & $95 \% \mathrm{Cl}$ & $\mathbf{N}$ & Prev (\%) & $95 \% \mathrm{Cl}$ \\
\hline \multirow[t]{3}{*}{ Mississippi Scale } & Cutting-Score $\geq 107$ & 1190 & 6.0 & $4.4-7.6$ & 406 & 3.8 & $1.4-6.2$ \\
\hline & Cutting-Score $\geq 94$ & 1190 & 15.3 & $12.5-18.1$ & 406 & 8.3 & $4.8-11.8$ \\
\hline & Cutting-Score $\geq 89$ & 1190 & 20.9 & |7.8-24.| & 406 & 11.2 & $7.3-15.2$ \\
\hline \multirow[t]{2}{*}{ One Month D-PTSD (DSM-III-R) } & All-Cause PTSD & 1197 & 3.5 & $2.3-4.8$ & 412 & 1.6 & $0.0-3.1$ \\
\hline & Combat-Related PTSD & 1197 & 3.3 & $2.1-4.6$ & 412 & 0.0 & $0.0-0.3$ \\
\hline \multirow[t]{2}{*}{ Lifetime D-PTSD (DSM-III-R) } & All-Cause PTSD & 1197 & 8.9 & $6.9-10.8$ & 412 & 4.6 & $2.2-7.1$ \\
\hline & Combat-Related PTSD & 1197 & 7.9 & $6.0-9.8$ & 412 & 0.1 & $0.0-0.2$ \\
\hline
\end{tabular}

PTSD, respectively. Similarly for the Male Vietnam-Era Controls, the MISS-PTSD estimates ranged from $12.1 \%$ to $26.3 \%$ while the MMPI-PTSD ranged from $10.1 \%$ to $28.1 \%$. For the D-PTSD, PTSD prevalence estimates ranged from $0.3 \%$ to $3.8 \%$ depending on the trauma and whether symptoms were experienced currently or previously.

\section{VES}

The prevalence estimates for the individual items used for the DIS-III-A PTSD module are presented in Table 4. All data presented represent symptoms that occurred within the last month of the PTSD interview and many years after the war's end. For Criterion B symptoms, using the organizational structure of DSM-III-R, the current prevalence estimates ranged from $1.9 \%$ for "felt as if event recurring" to $7.6 \%$ for "recurrent thoughts or dreams" for the male Vietnam-Theater-Veterans. For the male Vietnam-Era Controls, the Criterion B symptom current prevalences did not exceed $0.1 \%$ for any of the three symptoms. For the Criterion C symptoms, the symptom with the highest current prevalence was "avoiding situations that remind the person of past experiences" for both groups. Finally, for Criterion D symptoms, the highest prevalence estimate for the Vietnam-Theater-Veterans was "feeling jumpy or easily startled "(10.6\%). For the Era-Controls, the highest one month prevalence was the same item "feeling jumpy or easily startled" $(0.3 \%)$.

The current prevalence estimates for the summary measures from the VES are presented in Table 5. For the Vietnam-Theater-Veterans, the MMPI-PTSD prevalence estimates based on various cutting scores ranged from $6.4 \%$ to $34.2 \%$. For the male Vietnam Era-Controls, the MMPI-PTSD prevalence estimates ranged from $3.0 \%$ to $24.5 \%$. For current PTSD prevalence estimates using the DIS-III-A PTSD instrument and DSM-III criteria, $2.4 \%$ of the male Vietnam-Theater-Veterans were positively diagnosed as cases of combat-related PTSD. When DSM-III-R criteria were used, the current PTSD prevalence estimate increased to $4.7 \%$. There were no Vietnam-Era controls

Table 3: PTSD Scales Administered to NVVRS Clinical Subsample

\begin{tabular}{|c|c|c|c|c|c|c|c|}
\hline \multirow[t]{2}{*}{ Scale } & \multirow[t]{2}{*}{ Criteria } & \multicolumn{3}{|c|}{$\begin{array}{c}\text { Male Vietnam Theater } \\
\text { Veterans }\end{array}$} & \multicolumn{3}{|c|}{ Male Vietnam Era Controls } \\
\hline & & $\mathbf{N}$ & Prev (\%) & $95 \% \mathrm{Cl}$ & $\mathbf{N}$ & Prev (\%) & $95 \% \mathrm{Cl}$ \\
\hline \multirow[t]{3}{*}{ Mississippi Scale } & Cutting-Score $\geq 107$ & 259 & 7.0 & $3.8-10.2$ & 55 & 12.1 & I.0-23.2 \\
\hline & Cutting-Score $\geq 94$ & 259 & 14.9 & $10.3-19.5$ & 55 & 19.0 & $5.1-33.0$ \\
\hline & Cutting-Score $\geq 89$ & 259 & 20.4 & $|4.7-26|$. & 55 & 26.3 & $16.0-36.6$ \\
\hline \multirow[t]{3}{*}{ MMPI-Keane Scale } & Cutting-Score $\geq \mathbf{3 0}$ & 232 & 3.8 & $1.0-6.6$ & 50 & 10.1 & $0.0-23.2$ \\
\hline & Cutting-Score $\geq 26$ & 232 & 5.9 & $2.6-9.3$ & 50 & 10.1 & $0.0-23.2$ \\
\hline & Cutting-Score $\geq 14$ & 232 & 14.5 & $9.9-19.2$ & 50 & 28.1 & II.8-44.3 \\
\hline \multirow[t]{2}{*}{ One Month D-PTSD (DSM-III-R) } & All-Cause PTSD & 259 & 3.4 & $1.0-5.8$ & 57 & 0.3 & $0.0-0.8$ \\
\hline & Combat-Related PTSD & 259 & 3.3 & $0.9-5.7$ & 57 & 0.3 & $0.0-0.8$ \\
\hline \multirow[t]{2}{*}{ Lifetime D-PTSD (DSM-III-R) } & All-Cause PTSD & 259 & 10.8 & $6.3-15.2$ & 57 & 3.8 & $0.0-10.8$ \\
\hline & Combat-Related PTSD & 259 & 10.1 & $5.8-14.5$ & 57 & 0.3 & $0.0-10.8$ \\
\hline
\end{tabular}

I. Confidence Intervals that were less than 0 were truncated to 0 . 
Table 4: PTSD Items Administered Using DIS-III A Instrument in VES

\begin{tabular}{|c|c|c|c|c|c|}
\hline \multicolumn{2}{|c|}{$\begin{array}{l}\text { DSM-III-R Symptoms Occurring within Last Month } \\
\text { Criteria }\end{array}$} & \multicolumn{2}{|c|}{$\begin{array}{l}\text { Male Vietnam Theater Veterans } \\
\qquad(\mathbf{N}=\mathbf{2 , 4 8 3})\end{array}$} & \multicolumn{2}{|c|}{$\begin{array}{l}\text { Male Vietnam Era Controls } \\
\qquad(\mathbf{N}=1,976)\end{array}$} \\
\hline & & Prev (\%) & $95 \% \mathrm{Cl}$ & Prev (\%) & $95 \% \mathrm{Cl}$ \\
\hline \multirow[t]{3}{*}{ B } & Recurrent thoughts or dreams & 7.6 & $6.6-8.6$ & 0.1 & $0.0-0.3$ \\
\hline & Felt as if event recurring & 1.9 & $1.4-2.4$ & 0.0 & NA \\
\hline & Symptoms get worse in situations that remind & 3.9 & $3.1-4.7$ & 0.1 & $0.0-0.3$ \\
\hline \multirow[t]{3}{*}{ C } & Lost ability to care/Lost interest in activities & 5.1 & $4.2-6.0$ & 0.1 & $0.0-0.3$ \\
\hline & Avoids situations that remind & 7.9 & $6.8-9.0$ & 0.2 & $0.0-0.4$ \\
\hline & Ashamed of being alive & 1.9 & $1.4-2.4$ & 0.1 & $0.0-0.3$ \\
\hline \multirow[t]{3}{*}{$\mathbf{D}$} & Jumpy or easily startled & 10.6 & $9.4-11.8$ & 0.3 & $0.0-0.6$ \\
\hline & Trouble Sleeping & 7.4 & $6.4-8.4$ & 0.2 & $0.0-0.4$ \\
\hline & Forgetful or trouble concentrating & 5.2 & $4.3-6.1$ & 0.1 & $0.0-0.3$ \\
\hline
\end{tabular}

diagnosed with current combat-related PTSD using the DIS-III-A PTSD instrument.

For lifetime combat-related PTSD prevalence estimates (i.e. now or ever in the lifetime), $14.7 \%$ of the male Vietnam Theater-Veterans were identified as cases using the DIS-III-A PTSD instrument and DSM-III criteria while $27.4 \%$ were characterized as cases using the DIS-III-A PTSD instrument and DSM-III-R criteria. A very small percentage of the Controls were identified as cases using the DIS-III-A PTSD instrument and lifetime DSM criteria for combat-related PTSD (0.6\% for DSM-III and $1.1 \%$ for DSM-III-R). When DSM-III-R criteria were used, the PTSD prevalence estimates nearly doubled for both current and lifetime PTSD estimates.

\section{Comparisons of prevalence estimates: NVVRS vs. VES}

Table 6 presents the composite estimates for combatrelated PTSD from both samples. The composite diagnosis for the NVVRS used the cutting score of 94 for the MISS-PTSD while the composite diagnosis for the VES used a cutting score of 26 for the MMPI-PTSD. We focus on comparisons of DSM-III-R prevalence estimates as the estimates could be calculated from both studies. For the male Vietnam-Theater-Veterans, the narrow prevalence estimates for the NVVRS and VES were 2.9\% and 2.5\% respectively. The broad prevalence estimates were $15.8 \%$ and $12.2 \%$ respectively. For the male Vietnam-Era controls, a comparison of the prevalence rates across the two studies is less helpful given the focus on combat-related PTSD. For the narrow prevalence estimates, the NVVRS and VES both obtained estimates of $0.0 \%$ while for the broad estimates, the two studies yielded estimates of $8.3 \%$ and $4.8 \%$ respectively.

\section{Comparison of NVVRS "VES-Like" to "Non-VES-Like" subjects}

Similar to the previous analyses carried out by the NVVRS research team [82], there were no statistically significant differences on any of the outcome measures comparing the "VES-Like" subjects to the "Non-VES-Like" subjects for either the male Vietnam-Theater-Veterans or the male Vietnam-Era-Veterans.

\section{Discussion}

The results of this study provide additional insight into the sources of the disparate rates of PTSD reported in the VES and NVVRS, conducted by two independent groups of investigators. The use of a similar methodology to assess clinically relevant PTSD criteria and symptoms

Table 5: PTSD Scales Administered to VES Sample

\begin{tabular}{|c|c|c|c|c|c|c|c|}
\hline \multirow[t]{2}{*}{ Scale Criteria } & \multirow[t]{2}{*}{ Criteria } & \multicolumn{3}{|c|}{$\begin{array}{l}\text { Male Vietnam Theater } \\
\text { Veterans }\end{array}$} & \multicolumn{3}{|c|}{ Male Vietnam Era Controls } \\
\hline & & $\mathbf{N}$ & Prev (\%) & $95 \% \mathrm{Cl}$ & $\mathbf{N}$ & Prev (\%) & $95 \% \mathrm{Cl}$ \\
\hline \multirow[t]{3}{*}{ MMPI-Keane Scale } & Cutting-Score $\geq \mathbf{3 0}$ & 2,483 & 6.4 & $5.4-7.4$ & 1,976 & 3.0 & $2.2-3.8$ \\
\hline & Cutting-Score $\geq 26$ & 2,483 & 10.0 & $8.8-11.2$ & 1,976 & 4.8 & $3.9-5.7$ \\
\hline & Cutting-Score $\geq 14$ & 2,483 & 34.2 & $32.3-36.1$ & 1,976 & 24.5 & $22.6-26.4$ \\
\hline \multirow[t]{2}{*}{ One Month DIS-III-A PTSD } & DSM-III Combat-Related PTSD & 2,483 & 2.4 & $1.8-3.0$ & 1,976 & 0.0 & $0.0-0.1$ \\
\hline & DSM-III-R Combat-Related PTSD & 2,483 & 4.7 & $3.9-5.5$ & 1,976 & 0.0 & $0.0-0.1$ \\
\hline \multirow[t]{2}{*}{ Lifetime DIS-III-A PTSD } & DSM-III Combat-Related PTSD & 2,483 & 14.7 & $13.3-16.1$ & 1,976 & 0.6 & $0.3-0.9$ \\
\hline & DSM-III-R Combat-Related PTSD & 2,483 & 27.4 & $25.6-29.2$ & 1,976 & 1.1 & $0.6-1.6$ \\
\hline
\end{tabular}


Table 6: Summary of Broad and Narrow PTSD Criteria for the NVVRS and VES Samples

\begin{tabular}{|c|c|c|c|c|c|c|c|}
\hline \multirow[t]{2}{*}{ Scales } & \multirow[t]{2}{*}{ Criteria } & \multicolumn{3}{|c|}{$\begin{array}{l}\text { Male Vietnam Theater } \\
\text { Veterans }\end{array}$} & \multicolumn{3}{|c|}{ Male Vietnam Era Controls } \\
\hline & & $\mathbf{N}$ & Prev (\%) & $95 \% \mathrm{Cl}$ & $\mathbf{N}$ & Prev (\%) & $95 \% \mathrm{Cl}$ \\
\hline \multirow[t]{2}{*}{ NVVRS Current PTSD Diagnosis } & Broad-DSM-III-R' & 1,188 & 15.8 & $12.9-18.6$ & 406 & 8.4 & $4.9-11.9$ \\
\hline & Narrow-DSM-III-R' & 1,188 & 2.9 & $1.7-4.1$ & 406 & 0.0 & $0.0-0.1$ \\
\hline \multirow[t]{4}{*}{ VES Current PTSD Diagnosis } & Broad-DSM-III2 & 2,483 & 10.7 & $9.5-11.9$ & 1,976 & 4.8 & $3.9-5.7$ \\
\hline & Narrow-DSM-III2 & 2,483 & 1.7 & $1.2-2.2$ & 1,976 & 0.0 & NA \\
\hline & Broad-DSM-III-R' & 2,483 & 12.2 & $10.9-13.5$ & 1,976 & 4.8 & $3.9-5.7$ \\
\hline & Narrow-DSM-III-R' & 2,483 & 2.5 & I.9-3.1 & 1,976 & 0.0 & NA \\
\hline
\end{tabular}

I. Based on DSM-III-R definition for the DIS instrument.

2. Based on DSM-III definition for the DIS instrument.

resulted in consistent and understandable results across the two studies for male Vietnam Theater-Veterans. Specifically, the prevalence estimates of combat-related PTSD for male Vietnam Theater-Veterans was $2.5 \%$ using the VES and $2.9 \%$ using the NVVRS with restrictive criteria. Using more sensitive thresholds, the estimates were also quite similar across the two studies; $12.2 \%$ using the VES and $15.8 \%$ using the NVVRS. The discrepancies in the originally reported prevalence rates $[19,21]$ can be attributed to several factors:the NVVRS opted for more sensitive cutting-scores while the VES opted for more specific cutting-scores; the NVVRS used a six month prevalence estimate for current PTSD while the VES used a one month prevalence estimate for current PTSD and the VES used a single indicator for estimating prevalence whereas the NVVRS used multiple, fungible indicators.

In one study, the DIS-III-A PTSD measure was criticized as being an invalid measure of PTSD [82] and the poor validity of the instrument was put forward as the reason for the low prevalence estimates reported in the VES. Issues surrounding sensitivity and specificity often lead to the misinterpretation of similarities and differences in prevalence rates when comparing results across studies. [89-93] The results from our efforts at reconciliation suggest that the original VES study used very specific criteria for estimating the prevalence of PTSD (i.e. they only included symptoms that met criteria for each symptom and they used fewer symptom probes) while the NVVRS used very sensitive criteria for estimating the prevalence of PTSD (i.e. they included symptoms that were below criteria for each symptom and they included more symptom probes). Even though the DIS-III-A PTSD included fewer PTSD probes relative to the D-PTSD, we demonstrated that the DIS-III-A PTSD still retained enough items to provide useful data for estimating the prevalence of PTSD, especially when used in conjunction with another instrument such as the MMPI-PTSD.
Estimates of disease prevalence can vary dramatically depending on the time scale sampled (i.e. one month versus 6 month estimates). In establishing current PTSD, NVVRS inquired about PTSD symptoms recalled in the last 6 months while the VES inquired about symptoms in the last month. It should not be surprising that when we compared data for similar time frames following a severe trauma, the NVVRS and VES were more similar in terms of their prevalence estimates for PTSD.

Consistent and reliable measurement of complex psychological constructs such as PTSD is critical to advancing our understanding of both the etiology and treatment of psychological disorders. [72] The Institute of Medicine has recently been charged with reviewing the previous literature and recommending a reliable measure of PTSD for Gulf War veterans. [94] In general, single indicator models of psychological constructs are considered to be both less reliable and less valid measures compared to multiple indicator models. [72-74] Increasing the number of reliable probes used to measure psychological constructs results in an associated increase in the overall reliability of the instrument. For the NVVRS, the D-PTSD module included 21 symptom probes while for the VES study, the DIS-III-A PTSD module included only 9 symptom probes. Therefore, assuming equal reliability among the individual items, the NVVRS provided a more reliable estimate of combat-related PTSD prevalence relative to the VES. Finally, we agree with Kulka and colleagues [82] that the differences between the NVVRS and the VES were due to differences in instrumentation rather than due to differences in samples.

\section{Conclusion}

The results of our study highlight the benefits of applying uniform criteria across studies when comparing results and help to resolve some of the previously reported discrepant results in the literature. We also highlight the implications of using different thresholds for estimating 
the prevalence of combat-related PTSD. We strongly suggest that future comparisons of combat-related PTSD prevalence estimates use available sensitivity and specificity data to adjust observed prevalence estimates in order to compare estimates of the true population prevalences, within and across wars to detect secular changes. Finally, and sadly, with the beginning of several new wars throughout the international community, future studies of combat-related PTSD should consider the use of similar PTSD instruments to the ones used in the VES and NVVRS to allow for direct comparisons of prevalence estimates and predisposing factors across wars.

\section{Competing interests}

The author(s) declare that they have no competing interests.

\section{Authors' contributions}

Dr. Thompson was responsible for writing the manuscript, data analyses, and interpretation of the results. Dr. Gottesman was responsible for acquiring data, interpretation of the results and revising and editing the manuscript. Dr. Zalewski was responsible for interpretation of the results and revising and editing the manuscript.

\section{Acknowledgements}

We wish to thank Drs. Dan and Lynda King for their helpful comments on earlier drafts of the manuscript. The content of this publication does not necessarily reflect the views or policies of the Department of Health and Human Services, nor does mention of trade names, commercial products, or organizations imply endorsement by the U.S. Government.

\section{References}

I. Turnbull GJ: A review of post-traumatic stress disorder. Part I: Historical development and classification. Injury 1998, 29:87-9l.

2. Turnbull G]: A review of post-traumatic stress disorder. Part II: Treatment. Injury 1998, 29:169-175.

3. Jones E, Wessely S: Psychiatric battle casualties: an intra- and interwar comparison. Br J Psychiatry 200I, I 78:242-247.

4. Jones E, Hodgins-Vermaas R, McCartney H, Everitt B, Beech C, Poynter $\mathrm{D}$, et al: Post-combat syndromes from the Boer war to the Gulf war: a cluster analysis of their nature and attribution. BMJ 2002, 324:321-324.

5. Jones E, Vermaas RH, McCartney H, Beech C, Palmer I, Hyams K, et al.: Flashbacks and post-traumatic stress disorder: the genesis of a 20th-century diagnosis. Br J Psychiatry 2003, I 82: I58-163.

6. Brett EA, Spitzer RL, Williams JB: DSM-III-R criteria for posttraumatic stress disorder. Am J Psychiatry I 988, I 45:I232-I236.

7. Kuhne A, Baraga E, Czekala J: Completeness and internal consistency of DSM-III criteria for post-traumatic stress disorder. J Clin Psychol 1988, 44:717-722.

8. Davidson J, Smith $\mathrm{R}$, Kudler $\mathrm{H}$ : Validity and reliability of the DSM-III criteria for posttraumatic stress disorder. Experience with a structured interview. J Nerv Ment Dis 1989, I 77:336-34l.

9. Feinstein A: Posttraumatic stress disorder: a descriptive study supporting DSM-III-R criteria. Am J Psychiatry I989, I46:665-666

10. Solomon SD, Canino G]: Appropriateness of DSM-III-R criteria for posttraumatic stress disorder. Compr Psychiatry 1990, 3 I :227-237.

II. Wessely S: Risk, psychiatry and the military. Br J Psychiatry 2005, I 86:459-466.

12. Watson CG, Juba MP, Manifold V, Kucala T, Anderson PE: The PTSD interview: rationale, description, reliability, and con- current validity of a DSM-III-based technique. I Clin Psychol 1991, 47:179-188.

13. Zalewski C, Thompson W, Gottesman I: Comparison of Neuropsychological Test Performance in PTSD, Generalized Anxiety Disorder, and Control Vietnam Veterans. Assessment 1994, I:133-142.

14. Fukuda K, Nisenbaum R, Stewart G, Thompson WW, Robin L, Washko RM, et al:: Chronic multisymptom illness affecting Air Force veterans of the Gulf War. JAMA 1998, 280:98I-988.

15. Kinzie JD, Goetz RR: A century of controversy surrounding posttraumatic stress stress-spectrum syndromes: the impact on DSM-III and DSM-IV. J Trauma Stress 1996, 9: I59-I79.

16. Maes M, Delmeire L, Schotte C, Janca A, Creten T, Mylle J, et al.: Epidemiologic and phenomenological aspects of post-traumatic stress disorder: DSM-III-R diagnosis and diagnostic criteria not validated. Psychiatry Res 1998, 81:179-193.

17. Bland SH, O'Leary ES, Farinaro E, Jossa F, Trevisan M: Long-term psychological effects of natural disasters. Psychosom Med 1996, 58:18-24.

18. Basoglu M, Salcioglu E, Livanou M, Ozeren M, Aker T, Kilic C, et al: A study of the validity of a screening instrument for traumatic stress in earthquake survivors in Turkey. J Trauma Stress 2001, | 4:49|-509.

19. Kulka RA, Schlenger WE, Fairbank JA, Hough RL, Jordan BK, Marmar CR, et al.: Trauma and the Vietnam War Generation: Report Findings from the National Vietnam Veterans Redajustment Study New York: Brunner/ Mazel; 1990

20. Thompson KM, Crosby RD, Wonderlich SA, Mitchell JE, Redlin J, Demuth G, et al.: Psychopathology and sexual trauma in childhood and adulthood. J Trauma Stress 2003, 1 6:35-38.

21. US Centers for Disease Control: Health status of Vietnam veterans. I. Psychosocial characteristics. The Vietnam Experience Study. JAMA 1988, 259:270I-2707.

22. Wang X, Gao L, Shinfuku N, Zhang H, Zhao C, Shen Y: Longitudinal study of earthquake-related PTSD in a randomly selected community sample in north China. Am J Psychiatry 2000, I 57:1260-1266.

23. Sutker PB, Winstead DK, Galina ZH, Allain AN: Assessment of long-term psychosocial sequelae among POW survivors of the Korean Conflict. J Pers Assess 1990, 54: I70-180.

24. Engdahl BE, Speed N, Eberly RE, Schwartz J: Comorbidity of psychiatric disorders and personality profiles of American World War II prisoners of war. J Nerv Ment Dis 199I, I79:181-187.

25. Solomon Z, Neria Y, Ohry A, Waysman M, Ginzburg K: PTSD among Israeli former prisoners of war and soldiers with combat stress reaction: a longitudinal study. Am J Psychiatry |994, I 5 |:554-559.

26. King DW, King LA, Erickson DJ, Huang MT, Sharkansky EJ, Wolfe J: Posttraumatic stress disorder and retrospectively reported stressor exposure: a longitudinal prediction model. J Abnorm Psychol 2000, 109:624-633.

27. McFarlane AC: Long-term psychiatric morbidity after a natural disaster. Implications for disaster planners and emergency services. Med J Aust 1986, I 45:561-563.

28. McFarlane AC: The longitudinal course of posttraumatic morbidity. The range of outcomes and their predictors. J Nerv Ment Dis 1988, I 76:30-39.

29. McFarlane AC: The prevalence and longitudinal course of PTSD. Implications for the neurobiological models of PTSD. Ann N Y Acad Sci 1997, 82 1: 10-23.

30. Solomon Z, Mikulincer M, Waysman M, Marlowe DH: Delayed and immediate onset posttraumatic stress disorder. I. Differential clinical characteristics. Soc Psychiatry Psychiatr Epidemiol I991, 26: $1-7$.

31. Ursano RJ, Fullerton CS, Kao TC, Bhartiya VR: Longitudinal assessment of posttraumatic stress disorder and depression after exposure to traumatic death. J Nerv Ment Dis 1995, 183:36-42.

32. Dirkzwager AJ, Bramsen I, van der Ploeg HM: The longitudinal course of posttraumatic stress disorder symptoms among aging military veterans. J Nerv Ment Dis 200I, I 89:846-853.

33. Zlotnick C, Bruce SE, Shea MT, Keller MB: Delayed posttraumatic stress disorder (PTSD) and predictors of first onset of PTSD in patients with anxiety disorders. J Nerv Ment Dis 200I, I 89:404-406. 
34. Salcioglu E, Basoglu M, Livanou M: Long-term psychological outcome for non-treatment-seeking earthquake survivors in Turkey. J Nerv Ment Dis 2003, 191:154-160.

35. Port CL, Engdahl B, Frazier P: A longitudinal and retrospective study of PTSD among older prisoners of war. Am J Psychiatry 200I, I 58: | 474- I479.

36. Mollica RF, Sarajlic N, Chernoff M, Lavelle J, Vukovic IS, Massagli MP: Longitudinal study of psychiatric symptoms, disability, mortality, and emigration among Bosnian refugees. JAMA 200I, 286:546-554.

37. Goldberg J, True WR, Eisen SA, Henderson WG: A twin study of the effects of the Vietnam War on posttraumatic stress disorder. JAMA 1990, 263:1227-I232.

38. True WR, Rice J, Eisen SA, Heath AC, Goldberg J, Lyons MJ, et al: A twin study of genetic and environmental contributions to liability for posttraumatic stress symptoms. Arch Gen Psychiatry 1993, 50:257-264

39. Lurie S, Geyer P: Genetic and environmental influences of twins in posttraumatic stress. Arch Gen Psychiatry 1994, 5I:838-839.

40. Comings DE, Muhleman D, Gysin R: Dopamine D2 receptor (DRD2) gene and susceptibility to posttraumatic stress disorder: a study and replication. Biol Psychiatry 1996, 40:368-372.

4I. Breslau N, Davis GC, Andreski P, Peterson EL, Schultz LR: Sex differences in posttraumatic stress disorder. Arch Gen Psychiatry 1997, 54:1044-1048.

42. McLeod DS, Koenen KC, Meyer JM, Lyons MJ, Eisen S, True W, et al.: Genetic and environmental influences on the relationship among combat exposure, posttraumatic stress disorder symptoms, and alcohol use. J Trauma Stress 200I, I 4:259-275.

43. Radant A, Tsuang D, Peskind ER, McFall M, Raskind W: Biological markers and diagnostic accuracy in the genetics of posttraumatic stress disorder. Psychiatry Res 2001, 102:203-215.

44. McKenzie N, Marks I, Liness S: Family and past history of mental illness as predisposing factors in post-traumatic stress disorder. Psychother Psychosom 200I, 70:163-165.

45. Koenen KC, Harley R, Lyons MJ, Wolfe J, Simpson JC, Goldberg J, et al.: A twin registry study of familial and individual risk factors for trauma exposure and posttraumatic stress disorder. Nerv Ment Dis 2002, 190:209-218.

46. Frueh BC, Elhai JD, Grubaugh AL, Monnier J, Kashdan TB, Sauvageot JA, et al.: Documented combat exposure of US veterans seeking treatment for combat-related post-traumatic stress disorder. Br J Psychiatry 2005, 186:467-472.

47. Wessely S: War stories: Invited commentaries on... Documented combat expsoures of US veterans seeking treatment for combat-related stress disorder. Br J Psychiatry 2005, I 86:473-475.

48. Tyrer P: Editor's response. Br J Psychiatry 2005, 187:91.

49. Spitzer RL, Williams JB: Revised diagnostic criteria and a new structured interview for diagnosing anxiety disorders. J Psychiatr Res I988, 22(Suppl I):55-85

50. Williams JB, Gibbon M, First MB, Spitzer RL, Davies M, Borus J, et al: The Structured Clinical Interview for DSM-III-R (SCID). II. Multisite test-retest reliability. Arch Gen Psychiatry 1992, 49:630-636.

5I. Spitzer RL, Williams JB, Gibbon M, First MB: The Structured Clinical Interview for DSM-III-R (SCID). I: History, rationale, and description. Arch Gen Psychiatry 1992, 49:624-629.

52. Robins LN, Helzer JE, Croughan J, Ratcliff KS: National Institute of Mental Health Diagnostic Interview Schedule. Its history, characteristics, and validity. Arch Gen Psychiatry |98|, 38:38I-389.

53. Robins LN, Helzer JE, Ratcliff KS, Seyfried W: Validity of the diagnostic interview schedule, version II: DSM-III diagnoses. Psychol Med 1982, I 2:855-870.

54. Robins LN, Helzer JE, Weissman MM, Orvaschel H, Gruenberg E Burke JD Jr, et al.: Lifetime prevalence of specific psychiatric disorders in three sites. Arch Gen Psychiatry 1984, 41:949-958.

55. Helzer JE, Robins LN, McEvoy L: Post-traumatic stress disorder in the general population. Findings of the epidemiologic catchment area survey. N Engl J Med 1987, 3 I7:1630-1634.

56. Helzer JE, Robins LN: The diagnostic interview schedule: its development, evolution, and use. Soc Psychiatry Psychiatr Epidemiol 1988, 23:6-16.
57. Erdman HP, Klein MH, Greist JH, Skare SS, Husted J], Robins LN, et al.: A comparison of two computer-administered versions of the NIMH Diagnostic Interview Schedule. J Psychiatr Res I992, 26:85-95.

58. Lindal E, Stefansson JG: The lifetime prevalence of anxiety disorders in Iceland as estimated by the US National Institute of Mental Health Diagnostic Interview Schedule. Acta Psychiatr Scand 1993, 88:29-34

59. Grayson DA, O'Toole BI, Marshall RP, Schureck RJ, Dobson M, Ffrench $M$, et al.: Interviewer effects on epidemiologic diagnoses of posttraumatic stress disorder. Am J Epidemiol 1996, I44:589-597.

60. Keane TM, Caddell JM, Taylor KL: Mississippi Scale for CombatRelated Posttraumatic Stress Disorder: three studies in reliability and validity. I Consult Clin Psychol 1988, 56:85-90.

6I. Sloan P, Arsenault L, Hilsenroth M, Harvill L: Use of the Mississippi scale for combat-related PTSD in detecting war-related, non-combat stress symptomatology. J Clin Psychol 1995, $51: 799-801$

62. Vreven DL, Gudanowski DM, King LA, King DW: The civilian version of the Mississippi PTSD Scale: a psychometric evaluation. J Trauma Stress 1995, 8:91-109.

63. Norris FH, Perilla JL: The revised Civilian Mississippi Scale for PTSD: reliability, validity, and cross-language stability. J Trauma Stress 1996, 9:285-298.

64. Lauterbach D, Vrana S, King DW, King LA: Psychometric properties of the Civilian version of the Mississippi PTSD Scale. J Trauma Stress 1997, 10:499-5I3.

65. Keane TM, Malloy PF, Fairbank JA: Empirical development of an MMPI subscale for the assessment of combat-related posttraumatic stress disorder. J Consult Clin Psychol I984, 52:888-89 I.

66. Watson CG, Kucala T, Manifold V: A cross-validation of the Keane and Penk MMPI scales as measures of post-traumatic stress disorder. I Clin Psychol 1986, 42:727-732.

67. Watson CG, Juba M, Anderson PE, Manifold V: What does the Keane et al. PTSD scale for the MMPI measure? J Clin Psychol 1990, 46:600-606.

68. Litz BT, Penk WE, Walsh S, Hyer L, Blake DD, Marx B, et al:: Similarities and differences between MMPI and MMPI-2 applications to the assessment of posttraumatic stress disorder. J Pers Assess 1991, 57:238-253.

69. Munley PH, Bains DS, Bloem WD, Busby RM: Post-traumatic stress disorder and the MMPI-2. J Trauma Stress 1995, 8: I7I- 78

70. Scotti JR, Sturges LV, Lyons JA: The Keane PTSD Scale extracted from the MMPI: sensitivity and specificity with Vietnam veterans. J Trauma Stress 1996, 9:643-650.

7I. Lyons JA, Wheeler-Cox T: MMPI, MMPI-2 and PTSD: overview of scores, scales, and profiles. J Trauma Stress 1999, I 2: I75- |83.

72. King DW, King LA: Validity issues in research on Vietnam veteran adjustment. Psychol Bull 1991, 109:107-124.

73. King DW, King LA, Fairbank JA, Schlenger WE, Surface CR: Enhancing the precision of the Mississippi Scale for Combat-Related Postraumatic Stress Disorder: An application of item response theory. Psychological Assessment 1993, 5:457-47].

74. King DW, King LA: Latent structure of the Mississippi Scale for Combat-Related Postraumatic Stress Disorder: Exploratory and higher order confirmatory factor analyses. Assessment 1994, I:275-291.

75. Watson CG, Plemel D, DeMotts J, Howard MT, Tuorila J, Moog R, et al.: A comparison of four PTSD measures' convergent validities in Vietnam veterans. I Trauma Stress 1994, 7:75-82

76. Kulka RA, Schlenger WE, Fairbank JA, Hough RL, Jordan BK, Marmar CR: The National Vietnam Veterans Readjustment Study: Tables of Findings and Technical Appendices New York: Brunner/Mazel; 1990.

77. Jordan BK, Marmar CR, Fairbank JA, Schlenger WE, Kulka RA, Hough RL, et al.: Problems in families of male Vietnam veterans with posttraumatic stress disorder. I Consult Clin Psychol 1992, 60:916-926

78. Zatzick DF, Marmar CR, Weiss DS, Browner WS, Metzler TJ, Golding $\mathrm{JM}$, et al:: Posttraumatic stress disorder and functioning and quality of life outcomes in a nationally representative sample of male Vietnam veterans. Am J Psychiatry 1997, I54:1690-1695.

79. Ruef AM, Litz BT, Schlenger WE: Hispanic ethnicity and risk for combat-related posttraumatic stress disorder. Cultur Divers Ethnic Minor Psychol 2000, 6:235-25I. 
80. US Centers for Disease Control: Health status of Vietnam veterans. II. Physical Health. The Vietnam Experience Study. JAMA 1988, 259:2708-27|4.

81. US Centers for Disease Control: Health status of Vietnam veterans. III. Reproductive outcomes and child health. The Vietnam Experience Study. JAMA 1988, 259:27I5-27I9.

82. Kulka RA, Schlenger WE, Fairbank JA, Jordan BK, Hough RL, Marmar $\mathrm{CR}$, et al:: Assessment of postraumatic stress disorder in the community: Prospects and pitfalls from recent studies of Vietnam veterans. J Consult Clin Psychol 1991, 3:547-560.

83. Spitzer RL, Williams JB, Gibbons M: Structured clinical interview for DSM-III-R, Non-patient version (SCI-NP-V) New York: New York State Psychiatric Institute, Biometrics Research Department; 1987.

84. Robins LN, Helzer JE, Croughan J, Ratcliff KS: National Institute of Mental Health Diagnostic Interview Schedule. Its history, characteristics, and validity. Arch Gen Psychiatry 1981, 38:38I-389.

85. Helzer JE, Robins LN, McEvoy LT, Spitznagel EL, Stoltzman RK, Farmer A, et al: A comparison of clinical and diagnostic interview schedule diagnoses. Physician reexamination of layinterviewed cases in the general population. Arch Gen Psychiatry 1985, 42:657-666.

86. US Centers for Disease Control: Vietnam Experience Study. Health status of Vietnam veterans: Synopsis Volume I. Atlanta: Centers for Disease Control; 1989.

87. US Centers for Disease Control: Vietnam Experience Study. Health status of Vietnam veterans: Psychological and neuropsychological evaluations Volume IV. Atlanta: Centers for Disease Control; 1989.

88. American Psychiatric Association: Diagnostic and statistical manual of mental disorders (Third Edition-Revised) 3rd edition. Washington, DC: American Psychiatric Association; 1987.

89. Lai TJ, Chang CM, Connor KM, Lee LC, Davidson JR: Full and partial PTSD among earthquake survivors in rural Taiwan. $J$ Psychiatr Res 2004, 38:3 13-322

90. Liao SC, Lee MB, Lee YJ, Huang TS: Hyperleptinemia in subjects with persistent partial posttraumatic stress disorder after a major earthquake. Psychosom Med 2004, 66:23-28.

91. Lewinsohn PM, Shankman SA, Gau JM, Klein DN: The prevalence and co-morbidity of subthreshold psychiatric conditions. Psychological Medicine 2004, 34:6I3-622.

92. Breslau N, Lucia VC, Davis CG: Partial PTSD versus full PTSD: an empirical examination of associated impairment. Psychological Medicine 2004, 34: I-I0.

93. Narrow WE, Rae DS, Robins LN, Regier DA: Revised prevalence estimates of mental disorders in the United States: using a clinical significance criterion to reconcile 2 surveys' estimates. Arch Gen Psychiatry 2002, 59:1।5-123.

94. Institute of Medicine. Post Traumatic Stress Disorder: A Review 2006 [http://www.iom.edu/cms/3793/324/0.aspx].

\section{Pre-publication history}

The pre-publication history for this paper can be accessed here:

http://www.biomedcentral.com/1471-244X/6/19/pre pub

\section{Publish with Biomed Central and every} scientist can read your work free of charge

"BioMed Central will be the most significant development for disseminating the results of biomedical research in our lifetime. "

Sir Paul Nurse, Cancer Research UK

Your research papers will be:

- available free of charge to the entire biomedical community

- peer reviewed and published immediately upon acceptance

- cited in PubMed and archived on PubMed Central

- yours - you keep the copyright
BioMedcentral 